Psychological Medicine, 1991, 21, 831-836

Printed in Great Britain

\title{
EDITORIAL
}

\section{Biological markers of depression ${ }^{1}$}

The recent advances in molecular genetics (Gershon et al. 1987) have given a new impetus to the search for biological markers of depression. It is now feasible to use molecular techniques to study the functional expression of specific genes associated with clearly defined marker abnormalities in patients with depression. Such studies could yield valuable information regarding the classification and aetiology of depressive disorder and would be a valuable approach to complement linkage study. While linkage study alone has the potential to demonstrate an association between a small area of the genome and a clinical diagnosis, it offers no information about disease mechanisms at the molecular level. Our present ability to conduct innovative functional molecular investigations is limited principally by the difficulty of demonstrating reliable biological abnormalities in groups of depressed patients.

More recent studies of biological markers in depression have used notably improved methodology incorporating large groups of carefully diagnosed, drug-free patients. This has resulted in the more convincing validation of some putative markers, and the undoing of others. A number of other important issues have emerged. First, is an identified biological abnormality a state marker, present only when the patient is depressed or (possibly more relevant for genetic studies) does it persist into clinical recovery and thus represent a trait abnormality, an indicator, perhaps, of vulnerability to the disorder? Secondly, what is the specificity of the proposed marker to depressive disorders? Does it occur in other conditions such as obsessional neurosis or panic disorder? Thirdly, can the biological abnormality be accounted for in terms of the epiphenomena of the depressed state such as weight loss or sleep disturbance? Some recent biological marker studies are considered below with these points in mind.

\section{STUDIES OF PERIPHERAL BLOOD CELLS}

Platelets and lymphocytes have been widely used in biological marker studies of depression, mainly because they are readily accessible and possess receptors that resemble pharmacologically monoamine receptors in the brain (Elliott, 1984). The platelet also has an active uptake mechanism for 5-HT similar to that of 5-HT nerve terminals (Sneddon, 1973). The platelet 5-HT uptake site can be labelled by tritiated imipramine and early reports suggested a striking decrease in the number of platelet imipramine binding sites in depressed patients (Briley et al. 1980). More recently the literature has been rather contradictory and a recent multicentre WHO study failed to find any evidence of diminished imipramine binding in a large series of unmedicated depressed patients (WHO, 1990). The status of lowered imipramine binding as a biological marker of depression is therefore dubious. The reasons for the discrepancies between different studies have been attributed variously to methodological errors in ligand-binding assay techniques, previous drug treatment or a modulatory effect of cortisol hypersecretion (Cowen, 1989; WHO, 1990).

Reports have continued to appear of increased brain 5- $\mathrm{HT}_{2}$ receptor density in post-mortem studies of depressed patients and suicide victims (Arora \& Meltzer, 1989a; Yates et al. 1990), though there are also negative studies (Cheetham et al. 1988). It is therefore of interest that some investigations have revealed an increase in the number of $5-\mathrm{HT}_{2}$ receptors in platelet preparations from depressed patients (Arora \& Meltzer, $1989 \mathrm{~b}$; Pandey et al. 1990). In our laboratory, however,

\footnotetext{
' Address for correspondence: Dr P. J. Cowen, MRC Unit of Clinical Pharmacology and University Department of Psychiatry, Littlemore Hospital, Oxford OX4 4XN.
} 
we found no difference in platelet $5-\mathrm{HT}_{2}$ receptor binding between drug-free depressed patients and controls (Cowen et al. 1987) but we have obtained consistent evidence that platelet 5-HT receptor $^{2}$ number is increased by tricyclic antidepressant treatment (Cowen et al. 1986, 1987). Clearly, persisting effects of previous tricyclic treatment could be an important confounding variable in the study of platelet 5- $\mathrm{HT}_{2}$ receptors in 'drug-free' depressed patients. Until further information on this point is available, claims that increased platelet $5-\mathrm{HT}_{2}$ receptor binding is a biological marker of depression should be received with caution.

In contrast to the discord that attends platelet binding studies there is good agreement that when lymphocytes from depressed patients are stimulated in vitro with isoprenaline there is a significant attenuation of the usual increase in cyclic adenosine monophosphate (cAMP). This indicates a subsensitivity of lymphocyte $\beta$-adrenoceptors, though whether this results from loss of $\beta$ adrenoceptors or their functional uncoupling from adenylate cyclase is unclear (Pandey et al. 1987; Halpern et al. 1988).

Interestingly, a recent study reported that the blunted lymphocyte cAMP response of depressed patients was restored to normal by a course of electroconvulsive therapy (ECT) (Mann et al. 1990), suggesting that subsensitivity of lymphocyte $\beta$-adrenoceptors is a state rather than a trait marker of depression. Why this subsensitivity should develop during depression is unknown but it could represent a secondary consequence of elevated catecholamine levels or cortisol hypersecretion (Halpern et al. 1988). If such mechanisms are indeed involved, the relevance of the subsensitivity of lymphocyte $\beta$-adrenoceptors to the direct aetiology of the depressed state would be rather questionable. Studies on the density of $\beta$-adrenoceptors in the cerebral cortex of depressed suicide victims have been contradictory with both increased (Mann et al. 1986) and decreased (De Paermentier et al. 1990) numbers of binding sites reported. The advent of isotopic methods of imaging brain receptors in vivo may allow resolution of this controversy (Sedvall et al. 1986).

\section{STUDIES OF CATION TRANSPORT}

Biochemical studies of erythrocytes and platelets have demonstrated an altered activity of the cation transport enzyme, sodium + potassium activated adenosine triphosphatase (the sodium pump), in unipolar depression and in the depressed and manic phases of bipolar illness (Naylor et al. 1973, 1974 a; Sengupta et al. 1980; Akagawa et al. 1980). Some studies have shown a normalization of these changes following clinical recovery or after treatment with lithium salts (Hokin-Neaverson $e t$ al. 1976; Naylor et al. 1974 b, 1977). These in vitro studies point to a state-related abnormality in cation transport in unipolar depression and bipolar illness (see Wood, 1987).

Our own investigations, using oral rubidium loading to study the activity of the sodium pump in vivo, have confirmed that drug-free manic patients have increased pump activity (Wood et al. 1989 a). However, of particular interest was the finding that the change in sodium pump activity produced by lithium was qualitatively different between manic patients and healthy controls (Wood et al. $1989 b, c$ ), suggesting that the sodium pump enzyme expressed in bipolar patients may have altered regulatory properties. This could indicate a trait abnormality in sodium pump genes/proteins.

We have also measured the adaptive 'up-regulatory' responses of the lymphocyte sodium pump in vitro to standard biochemical stimuli. We studied two groups of euthymic patients with DSMIII-R bipolar illness, one receiving no medication, the other taking lithium alone; all patients had been in clinical remission for at least six months. In both patient groups the usual up-regulation of the sodium pump was significantly attenuated compared to healthy controls (Wood et al. 1991). Our findings confirm and extend the earlier work of Naylor \& Smith (1981) who found similar changes but in patients recently recovered and withdrawn only briefly from psychotropic drug treatment. These results, pointing to a trait abnormality of sodium pump regulation in bipolar patients, are of particular interest in view of increasing knowledge of the molecular genetic diversity and control of sodium pump expression (Famborough, 1988). 


\section{STUDIES OF NEUROENDOCRINE RESPONSES}

Abnormalities in cortisol secretion are well established in depressive illness and are generally regarded as state markers of the disorder (Abou-Saleh, 1988). Recent studies, however, have cast doubt on the specificity of the association of cortisol hypersecretion with depression (Braddock, 1986) and have also indicated the important contribution that weight loss may make to the observed endocrine abnormalities (Mullen et al. 1986). Despite these caveats there is great interest in the role of corticotropin releasing hormone $(\mathrm{CRH})$ in the pathogenesis of both the hypersecretion of cortisol and other core features of the depressive state (Nemeroff, 1988).

CRH functions both as a hypothalamic releasing factor and as a neurotransmitter in cortex and limbic regions, and its administration to animals produces changes in neuroendocrine regulation, sleep and appetite that parallel those seen in human depressive disorders (Nemeroff, 1988). It has therefore been suggested that increased secretion of $\mathrm{CRH}$ may play an aetiological role in the development of depression, and there is some evidence to support this proposal. For example, the ACTH response to exogenous CRH is blunted in depressed patients (Amsterdam et al. 1987) and this has been taken as evidence for pre-existing $\mathrm{CRH}$ hypersecretion. A similar interpretation has been made of the decreased number of CRH binding sites found in the cerebral cortex from suicide victims (Nemeroff et al. 1988). There are also reports of increased CRH concentrations in cerebrospinal fluid (CSF) of depressed patients (Banki et al. 1987). Further studies on the specificity of CRH abnormalities for depression will be of great interest.

Neuroendocrine challenge tests are probably one of the most reliable ways of demonstrating abnormal monoamine function in depressed patients. There is general agreement that the growth hormone response to the $\alpha_{2}$-adrenoceptor agonist, clonidine, is blunted in depressed patients (see Katona et al. 1987) and it seems likely that this abnormality persists following recovery and withdrawal of antidepressant treatment (Mitchell et al. 1988). Recent findings, however, have revealed that the GH response to clonidine is also blunted in patients with panic disorder (Nutt, 1989), though this might be accounted for by the substantial co-morbidity of panic disorder and major depression (Stein et al. 1990). Another important issue is the effect of previous tricyclic antidepressant treatment. It has been established for some time that tricyclic antidepressant therapy may suppress the growth hormone response to clonidine (Corn et al. 1984), but recent studies suggest that this effect may still be apparent many months after tricyclic withdrawal (Schittecatte et al. 1989). Clearly this could pose problems in distinguishing the effect of illness from that of previous treatment.

There is also fairly good agreement that the prolactin response to drugs that increase brain 5-HT function (L-tryptophan, clomipramine, fenfluramine) is reduced in depressed patients, but factors such as weight loss may need to be taken into account (see Cowen \& Anderson, 1991). In addition, the growth hormone response to the 5-HT precursor, L-tryptophan, has been shown to be substantially attenuated in three large, well-controlled studies of major depression (Koyama \& Meltzer, 1986; Cowen \& Charig, 1987; Deakin et al. 1990). The endocrine responses to Ltryptophan are not diminished in patients with panic disorder (Charney \& Heninger, 1986) or obsessional neurosis (Charney et al. 1988). Recently, in collaboration with workers in Manchester we have found that both the prolactin and growth hormone responses to L-tryptophan are restored to normal following clinical recovery of depressed patients and withdrawal of antidepressant treatment (Upadhyaya et al. 1991).

Taken together these studies suggest that blunted 5-HT-mediated prolactin and growth hormone responses appear to have some specificity for the presence of depressive illness and probably represent a state marker of the disorder. Further studies are currently being undertaken to identify more precisely the nature of the abnormality in 5-HT synaptic function, and to determine if the presence of decreased 5-HT neuroendocrine responses has implications for treatment response and clinical outcome. 


\section{STUDIES OF SLEEP}

Impairment of sleep is a hallmark of depressive illness and the architecture of the sleep electroencephalogram (EEG) is often disturbed in a characteristic way (Reynolds \& Kupfer, 1987). An abnormally short latency to the onset of rapid eye movement (REM) sleep is a fairly common finding in depressive illness, though similar changes have been reported in other psychiatric disorders, including schizophrenia (Campbell \& Gillin, 1987). There is, however, growing interest in the possible persistence of shortened REM latency in recovered depressed patients who have been withdrawn from medication (Rush et al. 1986). There is also a report that patients with short REM latencies are more likely to have first-degree relatives similarly affected and that these relatives have a significantly increased risk of developing depressive disorders (Giles et al. 1988).

These findings offer the intriguing prospect of developing family-based studies in which the clinical diagnosis of depression can be correlated with a reliable biological trait marker. However, it must be noted that most of the patients whose sleep architecture has been studied longitudinally have repeated episodes of illness and are often withdrawn from medication for only short periods. In addition, not all workers agree that abnormal REM latency persists into clinical remission (Berger et al. 1989). Nevertheless, the tantalizing association between disturbances of sleep and affect makes such investigations well worth undertaking. In addition, the availability of ambulatory cassette EEG recording, which permits measurement of the sleep EEG in patients' own homes, greatly eases the technical and logistical difficulties associated with sleep laboratory studies (Sharpley et al. 1990).

\section{CONCLUSION}

Despite much effort there is still no biological marker of depression which reliably and specifically distinguishes depressed patients from those with other psychiatric disorders or from healthy controls. As far as trait markers are concerned the most promising candidates appear to be abnormalities in REM sleep, in cation transport mechanisms and in the growth hormone response to clonidine, while the blunted endocrine responses to L-tryptophan appear to be a fairly reliable state marker.

The potential application of molecular genetic techniques to the further study of these marker abnormalities lies in two main areas. First, application of molecular techniques, designed to investigate the transcription of RNA and the translation of polypeptides, to the study of reliable trait markers will potentially yield information about the genes and functional genetic abnormalities which contribute to the underlying predisposition to develop depression, and it is perhaps logical that these studies should be pursued initially. Secondly, however, it would be of interest to study, in a similar manner, the molecular mechanisms of reliable state related markers, as these might give valuable information about processes which lead directly to the development of symptoms in susceptible individuals, in response to triggering stressors.

\section{P. J. COWEN AND A. J. WOOD}

\section{REFERENCES}

Abou-Saleh, M. T. (1988). How useful is a dexamethasone suppression test? Current Opinion in Psychiatry 1, 60-65.

Akagawa, K., Watanabe, M. \& Tsukada, Y. (1980). Activity of NaKATPase in manic patients. Journal of Neurochemistry 35, 258-260.

Amsterdam, J. D., Maislin, G., Winokur, A., Kling, M. \& Gold, P. (1987). Pituitary and adrenocortical responses to the ovine corticotropin releasing hormone in depressed patients and healthy volunteers. Archives of General Psychiatry 44, 775-781.

Arora, R. C. \& Meltzer, H. Y. $(1989 a)$. Serotonergic measures in the brains of suicide victims: $5-\mathrm{HT}_{2}$ binding sites in frontal cortex of suicide victims and control subjects. American Journal of Psychiatry 146, 730-736.

Arora, R. C. \& Meltzer, H. Y. (1989b). Increased serotonin (5-HT 2 ) receptor binding as measured by ${ }^{3} \mathrm{H}$-lysergic acid diethylamide $\left({ }^{3} \mathrm{H}\right.$-LSD) in the blood platelets of depressed patients. Life Sciences 44, 725-734.

Banki, C. M., Bissette, G., Arato, M., O'Connor, I. \& Nemeroff, C. B. (1987). CSF corticotropin-releasing factor-like immunoreactivity in depression and schizophrenia. American Journal of Psychiatry 144, 873-877.

Berger, M., Riemann, D., Höchli, D. \& Spiegel, R. L. (1989). The cholinergic rapid eye movement sleep induction test with RS-86. Archives of General Psychiatry 46, 421-426. 
Braddock, L. E. (1986). Dexamethasone suppression test: fact or artefact? British Journal of Psychiatry 148, 363-37I.

Briley, M. S. R., Langer, S. Z., Raisman, R., Sechter, D. \& Zarifian, E. (1980). Tritiated imipramine binding sites are decreased in the platelets of untreated depressed patients. Science 209, 303-305.

Campbell, S. S. \& Gillin, J. C. (1987). Sleep measures in depression how sensitive - how specific? Psychiatric Annals 17, 647-653.

Charney, D. S. \& Heninger, G. R. (1986). Serotonin function in panic disorders. Archives of General Psychiatry 43, 1059-1065.

Charney, D. S., Goodman, W. K., Price, L. H., Woods, S. W., Rosmussen, S. A. \& Heninger, G. R. (1988). Serotonin function in obsessive compulsive disorder: a comparison of the effects of tryptophan and $\mathrm{m}$-chlorophenyl-piperazine in patients and healthy subjects. Archives of General Psychiatry 45, 177-185.

Cheetham, S. C., Crompton, M. R., Katona, C. L. E. \& Horton, R.W. (1988). Brain 5-HT ${ }_{2}$ receptor binding in depressed suicide victims. Brain Research 443, 272-280.

Corn, T., Thompson, C. \& Checkley, S. A. (1984). Effects of desipramine treatment upon central adrenoceptor function in normal subjects. British Journal of Psychiatry 145, 139-145.

Cowen, P.J. (1989). Biological markers in depression. Current Opinion in Psychiatry 2, 106-109.

Cowen, P. J. \& Anderson, I. M. (1991). Abnormal 5-HT neuroendocrine function in depression: association or artefact? In 5 Hydroxytryptamine in Mental Illness: A Spectrum of Ideas (ed. M. Sandler, A. Coppen and S. Harnett), pp. 124-142. Oxford University Press: Oxford.

Cowen, P. J. \& Charig, E. M. (1987). Neuroendocrine responses to intravenous tryptophan in major depression. Archives of General Psychiatry 44, 958-966.

Cowen, P. J., Geaney, D. P., Schächter, M., Green, A. R. \& Elliott, J. M. (1986). Desipramine treatment in normal subjects: effects on neuroendocrine responses to tryptophan and on platelet serotonin (5-HT)-related receptors. Archives of General Psychiatry 43, $61-67$.

Cowen, P. J., Charig, E. M., Fraser, S. \& Elliott, J. M. (1987). 5-HT receptor binding during depressive illness and tricyclic antidepressant treatment. Journal of Affective Disorders 13, 45-50.

Deakin, J. F. W., Pennell, I., Upadhyaya, A. J. \& Lofthouse, R. (1990). A neuroendocrine study of 5-HT function in depression: evidence for biological mechanisms of endogenous and psychosocial causation. Psychopharmacology 101, 85-92.

De Paermentier, F., Cheetham, S. C., Crompton, S. R. \& Horton, R (1990). Brain $\beta$-adrenoceptor binding sites in antidepressant-free depressed suicide victims. Brain Research 25, 71-72.

Elliott, J. M. (1984). Platelet receptor binding studies in affective disorder. Journal of Affective Disorder 8, 219-239.

Famborough, D. M. (1988). The sodium pump becomes a family Trends in Neurosciences 7, 325-328.

Gershon, E. S., Merril, C. R., Goldin, L. R., Delisi, L. E., Berrettini, W. H. \& Nurnberger, J. I. (1987). The role of molecular genetics in psychiatry. Biological Psychiatry 22, 1388-1405.

Giles, D. E., Biggs, M. M., Rush, A. J. \& Roffwarg, H. P. (1988). Risk factors in families of unipolar depression. I. Psychiatric illness and reduced REM latency. Journal of Affective Disorders 14, $51-60$

Halpern, J. P., Brown, R. P., Sweeney, J. A., Kocsis, J. H., Peters, A. \& Mann, J. J. (1988). Blunted $\beta$-adrenergic responsivity of peripheral blood mononuclear cells in endogenous depression. Archives of General Psychiatry 45, 241-246.

Hokin-Neaverson, M., Spiegel, D. A. \& Lewis, W. C. (1974). Deficiency of erythrocyte sodium pump activity in bipolar manic depressive psychosis. Life Sciences 15, 1739-1748.

Hokin-Neaverson, M., Burckhardt, W. \& Jefferson, J. W. (1976). Increased erythrocyte $\mathrm{Na}^{+}$pump and $\mathrm{Na}-\mathrm{KATPa} e$ activity during lithium therapy. Research Communications in Pathology and Pharmacology 14, 117-126.

Katona, C. L. E., Theodorou, A. E. \& Horton, R. W. (1987). Alpha2-adrenoceptors in depression. Psychiatric Developments 5, 129 150.

Koyama, T. \& Meltzer, H. Y. (1986). A biochemical and neuroendo- crine study of the serotonergic system in depression. In $\mathrm{New}$ Results of Depression Research (ed. H. Hippius), pp. 169-188. Springer-Verlag: Berlin.

Mann, J. J., Stanley, M., McBride, P. A. \& McEwen, B. S. (1986). Increase serotonin ${ }_{2}$ and $\beta$-adrenergic binding on frontal cortex of suicide victims. Archives of General Psychiatry 43, 954-959.

Mann, J. J., Mahler, J. C., Wilner, P. J., Brown, R. P., Johnson, K. S., Kocsis, J. H. \& Chen, J.-S. (1990). Normalisation of blunted lymphocyte $\beta$-adrenergic responsivity in melancholic inpatients by a course of electroconvulsive therapy. Archives of General Psychiatry 47, 461-464.

Mitchell, P. B., Bearn, J. A., Corn, T. H. \& Checkley, S. A. (1988). Growth hormone response to clonidine after recovery in patients with endogenous depression. British Journal of Psychiatry 152, 34-38.

Mullen, P. E., Linsell, C. R. \& Parker, D. (1986). Influence of sleep disruption and calorie restriction on biological markers for depression. Lancet ii, 1051-1055.

Naylor, G. J. \& Smith, A. H. W. (1981). Defective genetic control of sodium pump density in manic depressive psychosis. Psychological Medicine 11, 257-263.

Naylor, G. J., Dick, D. A. T., Dick, E. G., Le Poidevin, D. \& Whyte, S. F. (1973). Erythrocyte membrane cation carrier in depressive illness. Psychological Medicine 3, 502-508.

Naylor, G. J., Dick, D. A. T., Dick, E. G. \& Moody, J. P. (1974a) Lithium therapy and erythrocyte membrane cation carrier. Psychopharmacology 37, 81-86.

Naylor, G. J., Dick, D. A. T., Dick, E. G., Worral, E. P., Peet, M. Dick, P. \& Boardman, L. J. (1974b). Erythrocyte membrane cation carrier in mania. Psychological Medicine 6, 659-663.

Naylor, G. J., Smith, A. H. W., Boardman, L. J., Dick, D. A. T., Dick, E. G. \& Dick, P. (1977). Lithium and erythrocyte membrane cation carrier studies in normal and manic depressive subjects. Psychological Medicine 7, 228-233.

Nemeroff, C. B. (1988). The role of corticotropin-releasing factor in the pathogenesis of major depression. Pharmacopsychiatry 21, 76-82.

Nemeroff, C. B., Owens, M. J., Bissette, G., Andorn, A. C. \& Stanley, M. (1988). Reduced corticotropin releasing factor binding sites in the frontal cortex of suicide victims. Archives of General Psychiatry 45, 577-580.

Nutt, D. J. (1989). Altered central $\alpha_{2}$-adrenoceptor sensitivity in panic disorder. Archives of General Psychiatry 46, 165-169.

Pandey, G. N., Janicak, P. G. \& Davis, J. M. (1987). Decreased betaadrenergic receptors in the leucocytes of depressed patients. Psychiatry Research 22, 265-274.

Pandey, G. N., Pandey, S. C., Janicak, P. G., Marks, R. C. \& Davis, J. M. (1990). Serotonin-2 receptor binding sites in the platelets of depressed patients. Biological Psychiatry 28, 215-222.

Reynolds, C. F. \& Kupfer, D. J. (1987). Sleep research in affective illness. State of the art circa 1987. Sleep 10, 199-215.

Rush, A. J., Erman, M. K., Giles, D. E., Schlesser, M. A., Carpenter, G., Vasavade, N. \& Roffwang, H. P. (1986). Polysomnographic findings in recently drug-free and clinically remitted depressed patients. Archives of General Psychiatry 43, 199-215.

Schittecatte, M., Charles, G., Machowski, R. \& Wilmotte, J. (1989). Tricyclic wash-out and growth hormone response to clonidine. British Journal of Psychiatry 154, 850-863.

Sedvall, G., Fande, L., Persson, A. \& Wiesel, F.-A. (1986). Imaging of neurotransmitter receptors in the living human brain. Archives of General Psychiatry 43, 995-1005.

Sengupta, N., Datta, S. C., Sengupta, D. \& Bal, S. (1980). Platele and erythrocyte membrane ATPase activity in depression and mania. Psychiatry Research 3, 337-344

Sharpley, A. L., Gregory, C. A., Solomon, R. A. \& Cowen, P. J. (1990). Slow wave sleep and $5 \cdot \mathrm{HT}_{2}$ receptor sensitivity during maintenance tricyclic antidepressant treatment. Journal of Affective Disorders 19, 273-277.

Sneddon, J. M. (1973). Blood platelets as a model for monoamine containing neurones. Progress in Neurobiology 1, 151-187.

Stein, M. B., Tancer, M. E. \& Uhde, T. W. (1990). Major depression 
in patients with panic disorder: factors associated with course and compliance. Journal of Affective Disorders 19, 287-296.

Upadhyaya, A. K., Pennell, I., Cowen, P. J. \& Deakin, J. F. W. (1991). Blunted growth hormone and prolactin responses to Ltryptophan in depression: a state-dependent abnormality. Journal of Affective Disorders 21, 213-218.

Wood, A. J. (1987). Changes in cation transport during affective illness. Do they have therapeutic implications? Human Psychopharmacology 2, 197-210.

Wood, A. J., Aronson, J. K., Cowen, P. J. \& Grahame-Smith, D. G. $(1989 a)$. The measurement of transmembrane cation transport in vivo in acute manic illness. British Journal of Psychiatry 155, 501-504.

Wood, A. J., Elphick, M., Aronson, J. K. \& Grahame-Smith, D. G. $(1989 \mathrm{~b})$. The effect of lithium on cation transport measured in vivo in patients suffering from bipolar affective illness. British Journal of Psychiatry 155, 504-510.
Wood, A. J., Viswalingam, A., Glue, P., Aronson, J. K. \& GrahameSmith, D. G. $(1989 c)$. Measurement of cation transport in vivo in healthy volunteers after the oral administration of lithium carbonate. Clinical Science 76, 397-402.

Wood, A. J., Smith, C. E., Clarke, E. E., Cowen, P. J., Aronson, J. K. \& Grahame-Smith, D. G. (1991). Altered in vitro adaptive responses of lymphocyte $\mathrm{Na}^{+}, \mathrm{K}^{+}$-ATPase in patients with manic depressive psychosis. Journal of Affective Disorders 21, 199-206.

World Health Organization Collaborative Study (1990). Validity of imipramine platelet binding sites as a biological marker of endogenous depression. Pharmacopsychiatry 23, 113-117.

Yates, M., Leake, A., Candy, J. M., Fairburn, A. F., McKeith, I. G. \& Ferrier, I. N. (1990). 5- $\mathrm{HT}_{2}$ receptor changes in major depression. Biological Psychiatry 27, 489-496. 